\title{
Tick-borne encephalitis transmitted by unpasteurised cow milk in western Hungary, September to October 2011
}

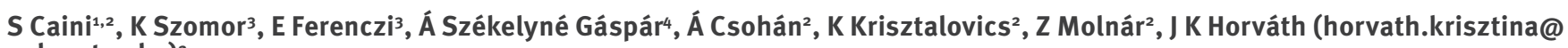
oek.antsz.hu) ${ }^{2}$

1. European Programme for Intervention Epidemiology Training (EPIET), European Centre for Disease Prevention and Control (ECDC), Stockholm, Sweden

2. Department of Infectious Disease Epidemiology, National Center for Epidemiology, Budapest, Hungary

3. National Reference Laboratory for Viral Zoonoses, National Center for Epidemiology, Budapest, Hungary

4. Körmendi, Őriszentpéteri, Szentgotthárdi, Vasvári Public Health Institute Service; Policy administration service of public health, Vas County Government Office, Körmend, Hungary

Caini S, Szomor K, Ferenczi E, Székelyné Gáspár Á, Csohán Á, Krisztalovics K, Molnár Z, Horváth JK. Tick-borne encephalitis transmitted by unpasteurised cow milk in western Hungary, September to October 2011.

Euro Surveill. 2012;17(12):pii=20128. Available online: http://www.eurosurveillance.org/ViewArticle.aspx?Articleld=20128

Article published on 22 March 2012

In October 2011, a cluster of four tick-borne encephalitis (TBE) cases was identified in Hungary. Initial investigations revealed a possible link with consumption of unpasteurised cow milk sold by a farmer without authorisation. We performed a cohort study including all regular customers of the farmer. Overall, eleven cases (seven confirmed and four suspected) were identified. Customers who had consumed the farmer's unpasteurised cow milk had more than a two-fold increased risk for being a TBE case, although not at statistically significant level.

\section{Introduction}

On 14 October 2011, the Department of Infectious Disease Epidemiology at the National Center of Epidemiology (NCE) in Budapest was alerted about a cluster of four hospitalised tick-borne encephalitis (TBE) cases that had occurred between 19 September and 1 October 2011, in the area surrounding $\mathrm{K}$, a small town in western Hungary close to the Austrian border. All four patients had already been interviewed by local public health authorities when NCE was alerted: none of them could remember having recently been bitten by a tick, but all of them referred to having consumed unpasteurised cow milk during the incubation period, which had been purchased from a farmer who has ten dairy cows producing about 70 litres milk per day. The milk of this farmer was sold without being pasteurised and without authorisation, to regular customers from approximately 40 families residing in four villages in the countryside surrounding $\mathrm{K}$. The farmer was forbidden to sell milk on 14 October 2011. On 18 October two epidemiologists from NCE went to K to help local public health staff with the epidemiological investigation.

The tick-borne encephalitis virus (TBEV) is an RNA virus belonging to the genus Flavivirus, family Flaviviridae. Three subtypes are described: European (the most common subtype in Europe), Siberian and Far Eastern. TBEV is transmitted by ticks, Ixodes ricinus being the most common vector in central Europe [1]. The virus can be transmitted by bites of infective ticks or, less frequently (but more successfully and with a shorter incubation period [2]), by consumption of unpasteurised milk from infected animals. Approximately two thirds of human TBE virus infections are asymptomatic. In clinical cases, TBE often has a biphasic course: after an incubation period of 7-14 days, infected people develop aspecific symptoms lasting approximately one week (first phase), followed, after a few days, by neurological symptoms (second phase) in approximately one third of those who experience first-phase symptoms [3]. The case fatality ratio is around $1-3 \%$ for the European and Siberian subtypes and $20 \%$ for the Far Eastern subtype [1]. Vaccine for the prevention of TBE is available. In Hungary, groups at risk such as forest workers, geologists and laboratory workers are advised to get vaccinated [4].

Two surveys were conducted in 2008 and 2011 respectively to collect information on incidence of TBE in the sixteen European countries where TBE is a notifiable disease $[5,6]$. Overall, 17,818 cases were reported from 2007 to 2009, 53\% coming from Russia. The highest annual incidence rates ( $10 / 100,000$ population) were observed in Baltic countries and Slovenia. A few TBE outbreaks caused by consumption of non-pasteurised goat and sheep milk and goat cheese were previously reported from central and northern Europe, including Hungary [7-13].

In Hungary, TBE is notifiable by law since 1977. Overall, 686 cases of TBE were reported from 2001 to 2010. According to NCE data, annual incidence rates were between $0.5-0.8 / 100,000$ inhabitants from 2001 to 2010. Males represented $70 \%$ of reported cases, and 
the age group with the highest number of reported cases was the 40-49 year old for both sexes.

The highest TBE incidence rates were observed in the West Transdanubian region of the country (Figure), where the present outbreak took place. Usually, indepth individual epidemiological investigations are performed only when a cluster of TBE cases in time and space is detected. In the last decade, two TBE outbreaks related to raw goat milk consumption were reported in 2007 and 2008 , with respectively 25 and two individuals affected $[7,14]$.

We aimed at investigating whether consumption of unpasteurised cow milk from the suspected farmer was associated with being a case.

\section{Methods}

Considering that the first case was observed on 11 September 2011, that the selling of milk was discontinued on 14 October 2011, and that the incubation period of TBE is usually 7-14 days, the study period extended from 28 August to 28 October 2011. All the members of the families who bought milk from the suspected farmer during the study period were considered as a cohort.

On 17 and 18 October face-to-face interviews were conducted at the houses of all families, using a standardised questionnaire. Information was obtained on demographics (age and sex), symptoms of TBE (first and second phase) during the study period, date of onset and duration of symptoms, outcome of the disease, tick bites during the study period, vaccination status against TBE, weekly quantity of milk bought during the study period, and type (raw, heat-treated or both) of cow milk consumed.

The anti-TBEV serology tests were performed by indirect immunofluorescence assay for TBE virus-specific

\section{FIGURE}

Empirical Bayesian smoothed indirect standardised incidence ratios of tick-borne encephalitis, by municipality, Hungary, for 1998-2008 and location of outbreaks related to the consumption of unpasteurised milk between 2007 and $2011^{*}$

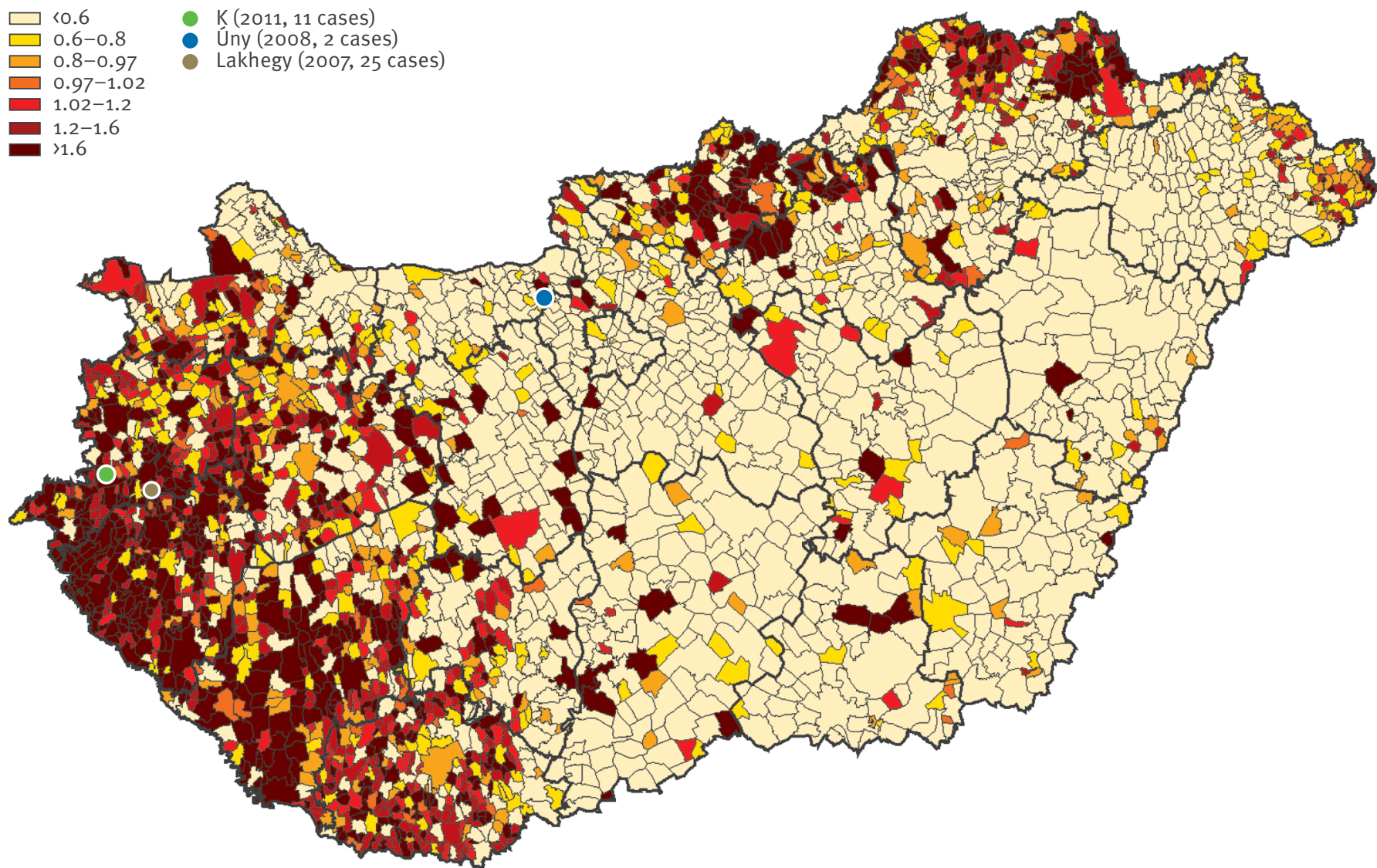

TBE: Tick-borne encephalitis.

A green dot indicates the TBE outbreak area reported in this study, which is related to the consumption of unpasteurised cow milk. A brown and a blue dot indicate respective locations of previous TBE outbreaks, which were related to consumption of raw goat milk.

Reproduced with permission from Zöldi V, National Center for Epidemiology, Hungary. [Zöldi V, Juhász A, Nagy C, Szilágyi A, Páldy A. Tickborne encephalitis and Lyme borreliosis in Hungary - The epidemiological situation between 1998 and 2008 . ESCAIDE, Poster Session, Lisbon, 11-13 November 2010.]* 
IgM and IgG. Paired blood samples and/or cerebrospinal fluid (CSF) of patients with TBE clinical criteria were tested. Paired samples were tested in parallel on the same antigen slide. Specific slides with the first Hungarian TBEV isolate strain "Kem I" $[15,16]$ infected VERO cells were prepared in house. A twofold dilution series was made of each serum sample with phosphate buffered saline (PBS) starting at 1:10 and was titrated to determine the antibody titre end points. CSF samples were tested without dilution. The testing protocol was as described earlier [7].

Criteria for laboratory diagnosis of TBE were the presence of TBE virus-specific immunoglobulin $M$ (IgM) in CSF or in blood. TBE clinical criteria were defined as subfebrility $\left(37.0-38.0^{\circ} \mathrm{C}\right) /$ fever $\left(338.0^{\circ} \mathrm{C}\right)$ and malaise/ headache/dizziness, or encephalitis. Clinical samples for serology at NCE were obtained from patients who met at least one of the TBE clinical criteria and gave consent.

A confirmed case was a cohort member with disease onset between 28 August and 28 October 2011 including at least one TBE clinical criterion and one of the laboratory criteria. A suspected case was a cohort member with disease onset between 28 August and 28 October 2011 including at least one TBE clinical criterion and for whom a clinical sample for laboratory analysis was not available.

Exposure was defined as consumption of milk (only raw, only heat-treated, both raw and heat-treated) purchased from the suspected farmer during the study period.

Risk ratios (RRs) and risk differences (RDs) and their respective $95 \%$ confidence intervals $(95 \% \mathrm{Cl})$ were calculated to compare attack rate among consumers and non-consumers of milk (any milk or raw milk only) so as to investigate the possible association between consumption of unpasteurised cow milk and being a case.
Blood samples were taken from each of the farmer's 10 lactating cows on 17 October but proved to be not suitable for analysis. Milk samples were therefore taken from all 10 cows on 2 November 2011 and tested by polymerase chain reaction (PCR) for the TBE virus.

\section{Results}

The farmer declared to provide 41 families (112 people) with milk. One person did not wish to participate in the investigation, two people could not be contacted, and one person stated not having bought milk from the farmer in question. We also excluded from the cohort five people who were partly or fully vaccinated against TBE. Finally, 103 people ( 52 females, median age 46 years, range 1-96) from 36 families were included in the cohort.

Overall, eleven cases (seven females, median age 44 years, range 1-85) of TBE were reported (seven confirmed, including the four cases initially reported, and four suspected). One of the suspected cases, who was included in the cohort, had been hospitalised with clinical symptoms on TBE prior to NCE being alerted of the TBE cluster. This person had eventually died without having been tested for TBE virus. Of all cases $(n=11)$, only the four initially reported cases suffered from encephalitis. The seven confirmed (altogether 11) TBE cases clustered in six (altogether seven) of the 36 families in the cohort.

The table shows results of the analysis. No confirmed cases and only one suspected case were observed among those who did not drink any milk, the risk difference being significantly higher than the null value for confirmed cases. Those who reported any/raw milk consumption from the suspected farmer had more than twice the risk of developing the disease compared to those who reported not having drunk any/raw milk, although statistical significance was not reached.

Milk samples taken from the cows tested negative for the TBE virus.

\section{TABLE}

Attack rates among tick-borne encephalitis cases by exposure to unpasteurised cow milk, risk ratios and differences,

Hungary, September-October 2011

\begin{tabular}{|c|c|c|c|c|c|c|c|c|c|c|}
\hline \multirow[b]{2}{*}{$\begin{array}{l}\text { Inclusion criteria } \\
\text { for cases }\end{array}$} & \multirow[b]{2}{*}{$\begin{array}{l}\text { Exposure } \\
\text { type }\end{array}$} & \multicolumn{3}{|c|}{ Exposed } & \multicolumn{3}{|c|}{ Unexposed } & \multirow{2}{*}{$\begin{array}{c}\text { Risk ratio } \\
\text { (95\% Confidence } \\
\text { Interval) }\end{array}$} & \multirow{2}{*}{$\begin{array}{c}\text { Risk difference } \\
\text { (95\% Confidence } \\
\text { Interval) }\end{array}$} & \multirow{2}{*}{$\begin{array}{l}\text { Percentage of } \\
\text { cases explained } \\
\text { by exposure }\end{array}$} \\
\hline & & Cases & $\begin{array}{l}\text { Non- } \\
\text { cases }^{a}\end{array}$ & $\begin{array}{l}\text { Attack } \\
\text { rate }\end{array}$ & Cases & $\begin{array}{l}\text { Non- } \\
\text { cases }^{\text {a }}\end{array}$ & $\begin{array}{l}\text { Attack } \\
\text { rate }\end{array}$ & & & \\
\hline Confirmed $(\mathrm{N}=7)$ & Any milk ${ }^{b}$ & 7 & 78 & $8 \%$ & 0 & 18 & $0 \%$ & $-(-)$ & $8.2 \%(2.4$ to 14.1$)$ & $100 \%$ \\
\hline $\begin{array}{l}\text { Confirmed and } \\
\text { suspected }(\mathrm{N}=11)\end{array}$ & Any milk ${ }^{b}$ & 10 & 75 & $12 \%$ & 1 & 17 & $6 \%$ & $2.12(0.29$ to 15.52$)$ & $6.2 \%(-6.3$ to 18.8$)$ & $91 \%$ \\
\hline Confirmed $(\mathrm{N}=7)$ & Raw milk & 5 & 47 & $10 \%$ & 2 & 49 & $4 \%$ & $2.45(0.49$ to 12.07$)$ & $5.7 \%(-3.9$ to 15.3$)$ & $71 \%$ \\
\hline
\end{tabular}

a The number of non-cases is obtained by subtracting the number of cases $(\mathrm{N})$, as defined in the column "inclusion criteria for cases" from the total number of people in the cohort $(n=103)$ and then subsequently considering how many are in either exposed or unexposed categories. When only confirmed cases are considered as cases, the rest of the cohort, including suspected cases, constitutes non-cases.

b Any milk includes raw milk and raw milk that has been heat-treated but not pasteurised. 


\section{Discussion}

To our knowledge, this is the first report of a TBE outbreak supposedly transmitted by unpasteurised cow milk in the European Union (EU). Other reports were published about TBE outbreaks in the EU transmitted by goat $[7-11,13]$ and sheep [12] milk. A TBE outbreak transmitted by cow milk [17] was previously described in eastern Russia (close to the border with North Korea) where the Siberian and Far Eastern subtypes of TBE virus are more common than the European subtype.

Our investigation presents some methodological limitations. First, the statistical power of our investigation was rather low (less than 0.30), despite that all but three members of the cohort were interviewed. Second, only symptomatic cohort members were tested, while it is known that two thirds of people infected with TBE are completely asymptomatic: some misclassification of case-status is therefore very likely to have occurred. If we assumed that the number of infected cases would be three times the number of symptomatic cases, and re-calculated RRs according to this assumption, the point estimates would not change but RRs for consuming raw milk would reach statistical significance: RR:2.45 (1.03-5.82) for confirmed cases and RR:2.62 (1.35-5.07) for confirmed and suspected cases.

Misclassification of exposure may also have occurred concerning heat-treatment of milk. If we assume that cases and non-cases were comparably unaware of correct procedures for boiling milk [18], the misclassification of exposure would be non-differential, and the RR reported would be biased towards one. If, however, the non-cases were more likely to report that they had boiled the milk when the boiling was not effective, this misclassification would be differential, and the RR calculated would be overestimated.

Milk samples taken from the cows tested negative for TBEV. This is not fully surprising considering that the milk samples were taken on 2 November, i.e. 15 days after the last (suspected) case was observed. Balogh et al [19] showed that experimentally infected goats can shed TBEV in milk for more than twenty days after infection, but no data exist about persistence of TBEV in milk of infected cows.

The potential for the spreading of infectious diseases by drinking unpasteurised cow milk is well known. Concerning TBE, the proportion of cases infected via unpasteurised milk has been estimated to be $0.9 \%$ in Czech Republic from 1997 to 2008 [9] and 9\% in Slovakia [20]. Cisak et al found that more than $20 \%$ of goat and sheep milk samples and $11 \%$ of cow milk samples tested positive for TBEV in a survey in eastern Poland [21], an area with high incidence of TBE. Considering that cow milk is far more frequently consumed than goat and sheep milk, and that the habit of buying milk from small farmers (that may not fulfil all requirements for milk safety) is not rare, especially in the countryside, implication of consuming unpasteurised cow milk as cause of TBE outbreaks should not be overlooked.

TBE transmitted by unpasteurised milk could be effectively prevented by vaccinating people and/or dairy animals [19]; although it is not clear yet how long the immunity against TBEV persists in animals. However, many other infective agents (Mycobacterium bovis, Brucella spp., Campylobacter spp., Streptococcus spp., etc) may be transmitted by milk for which a vaccine is not available [1]. Therefore, public health services should primarily focus their efforts towards prohibiting the sale of milk by farmers without authorisation and informing the public about the risks associated with consumption of unpasteurised milk and the beneficial effects of boiling such milk before drinking or processing it.

\section{Acknowledgments}

Éva Stanitz, county chief medical officer, Vas County Government Office; Lászlo Szűcs, local chief medical officer, Vas County Government Office.

\section{* Authors' correction}

The title of the figure and the information regarding the source of the map were corrected on 31 July 2012 at the request of the authors.

\section{References}

1. Heymann DL, editor. Control of communicable disease manual, 19th Edition. Washington DC: American Public Health Association (APHA); 25 Oct 2008.

2. Dumpis U, Crook D, Oksi J. Tick-borne encephalitis. Clin Infect Dis. 1999;28(4):882-90.

3. Centers for Disease Control and Prevention (CDC). CDC Health Information for International Travel 2012. New York: Oxford University Press; 2012.

4. National Center for Epidemiology (NCE). Az Országos Epidemiológiai Központ módszertani levele a 2012. évi védóoltásokról [Hungarian Guideline on Vaccination for 2012]. Epinfo. 2012; 1. Special issue. Hungarian. Available from: http://www.oek.hu/oek.web?to=839,1991,1866,1992\&nid=106 5\&pid=1\&lang=hun

5. Donoso Mantke 0 , Schädler R, Niedrig M. A survey on cases of tick-borne encephalitis in European countries. Euro Surveill. 2008;13(17):pii=18848. Available from: http://www. eurosurveillance.org/ViewArticle.aspx?Articleld=18848

6. Donoso Mantke O, Escadafal C, Niedrig M, Pfeffer M. Tickborne encephalitis in Europe, 2007 to 2009. Euro Surveill. 2011;16(39):pii=19976. Available from: http://www. eurosurveillance.org/ViewArticle.aspx?Articleld=19976

7. Balogh Z, Ferenczi E, Szeles K, Stefanoff P, Gut W, Szomor $\mathrm{KN}$, et al. Tick-borne encephalitis outbreak in Hungary due to consumption of raw goat milk. J Virol Methods. 2010;163(2):481-5.

8. Holzmann H, Aberle SW, Stiasny K, Werner P, Mischak A, Zainer B, et al. Tick-borne encephalitis from eating goat cheese in a mountain region of Austria. Emerg Infect Dis. 2009;15(10):1671-3.

9. Kríz B, Benes C, Daniel M. Alimentary transmission of tick-borne encephalitis in the Czech Republic (1997-2008). Epidemiol Mikrobiol Imunol. 2009;58(2):98-103.

10. Kerbo N, Donchenko I, Kutsar K, Vasilenko V. Tickborne encephalitis outbreak in Estonia linked to raw goat milk, May-June 2005. Euro Surveill. 2005;10(25): pii=2730. Available from: http://www.eurosurveillance.org/ViewArticle. aspx?Articleld $=2730$ 
11. Kohl I, Kozuch O, Elecková E, Labuda M, Zaludko J. Family outbreak of alimentary tick-borne encephalitis in Slovakia associated with a natural focus of infection. Eur J Epidemiol. 1996;12(4):373-5.

12. Gresíková $M$, Sekeyová $M$, Stúpalová $S$, Necas S. Sheep milk-borne epidemic of tick-borne encephalitis in Slovakia. Intervirology. 1975;5(1-2):57-61.

13. Széles K, Oroszi B, Sustik T, Somfalvi Á, Szilvágyi Cs-né, Kalamár-Birinyi E, et al. Kecsketej által közvetített kullancsencephalitis járvány 2007 augusztus, Lakhegy (Zala megye) [Tick-borne encephalitis outbreak transmitted by goat milk, August 2007, Lakhegy (Zala county)]. Epinfo 2008;38: 449-55. Hungarian.

14. National Center for Epidemiology (NCE). Heti kiadványok 2008 , 38.hét [Weekly Epidemiological report 2008, week 38]. NCE: Budapest; 26 Sep 2008 . Hungarian. Available from: http:// www.oek.hu/oek.web?to $=839,1866,1489,1480 \&$ nid $=41 \&$ pid $=$ 8 \&lang=hun

15. Ecker M, Allison SL, Meixner T, Heinz FX. Sequence analysis and genetic classification of tick-borne encephalitis viruses from Europe and Asia. J Gen Virol. 1999;80(Pt 1):179-85.

16. Fornosi F, Molnár E. Tick encephalitis in Hungary, isolation of virus and its properties. Acta Microbiol Acad Sci Hung. 1954;1(1-3):9-21.

17. Vereta LA, Skorobrekha VZ, Nikolaeva SP, Aleksandrov VI,Tolstonogova VI, Zak-harycheva TA, et al. [The transmission of the tick-borne encephalitis virus via cow's milk]. Med Parazitol (Mosk). 1991;(3):54-6. Russian.

18. Abdussalam M, Bijlenga G, Kaplan MM. Diseases transmitted through milk. In: Milk Hygiene. World Health Organization/ Food and Agriculture Organization of the United Nations (WHO/ FAO) 1962. p.11-74.

19. Balogh Z, Egyed L, Ferenczi E, Bán E, Szomor KN, Takács $M$, et al. Experimental Infection of Goats with TickBorne Encephalitis Virus and the Possibilities to Prevent Virus Transmission by Raw Goat Milk. Intervirology. 2012;55(3):194-200.

20. Labuda M, Elecková E, Licková M, Sabó A. Tick-borne encephalitis virus foci in Slovakia. Int J Med Microbiol. 2002;291 Suppl 33:43-7.

21. Cisak E, Wójcik-Fatla A, Zając V, Sroka J, Buczek A, Dutkiewicz J. Prevalence of tick-borne encephalitis virus (TBEV) in samples of raw milk taken randomly from cows, goats and sheep in eastern Poland. Ann Agric Environ Med. 2010; 17(2):283-6. 